\title{
Quality of life in patients with oculocutaneous albinism*
}

\author{
Marcus Maia ${ }^{1,2}$ \\ Gabriela Alves dos Santos ${ }^{1}$
}

\author{
Beatrice Mussio Fornazier Volpini ${ }^{1}$ \\ Maria Josefa Penon Rujula ${ }^{1,2}$
}

DOI: http:/ / dx.doi.org/ 10.1590/ abd1806-4841.20153498

\begin{abstract}
A bstract: BACKGROUND: The social reality of the al bino needs to be more studied in Brazil, as myths and social segregation regarding this illness are likely to be found in the country, with psychosocial and medical implications. OBjectIVE: As this subject has not been referenced in previous scientific articles in Brazil, this research intends to evaluate the quality of life of the al binos that treated at our medical institution.

METHODS: The quality of life was evaluated through the WHOQOL-BREF. Furthermore, two aspects of main relevance in the lives of the al binos were also objects of research, low vision and skin cancer. The sample consisted of forty oculocutaneous al binos and a control group of forty healthy individuals, matched by sex and age.

RESULTS: Among the participants, 57.7\% were between 18 and 40 years old, 28.2\% were between 41 and 60, and $14.1 \%$ were over $60.42 .1 \%$ had skin cancer before the study, $18.4 \%$ had skin cancer during the study and $89.5 \%$ stated visual deficit. The results obtained in the questionnaires showed a statistically significant difference in the physical domain, with $\mathrm{P}<0.001$.

ConcLusion: Low vision combined with skin lesions and social stigma may contribute to disturbances in the quality of life of oculocutaneous al binos. The results presented in this study demonstrated the vulnerability of the affected individuals and the special care required by those patients, at the same time that the need for further research is highlighted in order to better elucidate the aspects related to al binism.
\end{abstract}

Keywords: Albinism; Albinism, oculocutaneous; Quality of life

\section{INTRODUCTION}

The word al binism derives from the Latin al bus (white) and refers to the inability of an individual or animal to produce melanin, the pigment that colors the skin and protects from ultraviolet radiation. It is a group of hereditary diseases where melanin biosynthesis is reduced or absent., ${ }^{1,2}$

It is estimated that one in 17,000 people in the world has one of the oculocutaneous al binism (OCA) types and that 1 in 70 individuals carries an OCA gene. ${ }^{3,4}$ Oculocutaneousal binism (OCA) type1(OCA 1) reaches approximately 1 in 40,000 individuals, in the majority of populations. ${ }^{3,4}$ The frequency of OCA2 in the USA is 1 in 36,000 births, 1 in 10,000 AfricanAmericans and 1 in 1,100 considering the Nigerian population in general. ${ }^{2}$ In Brazil, epidemiological studies are scarce. In a study about the OCA profile in the state of Bahia, it was found that $70 \%$ of albinos declared negro or mixed ascendance, similar to racial distribution in Bahia. ${ }^{5}$

In Africa, where albinism is more prevalent and better studied, there is growing evidence of social discrimination and stigmatization of this population; it is, therefore, a genetic condition that affects the individual and his family from a medical, social and psychological point of view. Due to the prejudice and discrimination to which these individuals are exposed in society, many tend to be more unstable emotionally and develop a less assertive personality than people without albinism. Thus, the quality of life of albinos is compromised, which may become evident in the child's performance and relationships at school, followed by difficulty in finding a job and a spouse, when compared to the rest of the population. ${ }^{6}$ Nevertheless, peoplewith OCA havenormal longevity, fertility and development. ${ }^{4}$

Received on 02.03.2014.

A pproved by theAdvisory Board and accepted for publication on 15.08.2014.

* Study carried out at Irmandade Santa Casa de Misericórdia de São Paulo- São Paulo (SP), Brazil.

Financial Support: Scientific Initiation Fellow PIBIC - Medical Science School, Charity Hospital (Santa Casa) of São Paulo. Conflict of Interests: None.

Irmandade Santa Casa de Misericórdia de São Paulo - São Paulo (SP), Brazil.

Faculdade de Ciências Médicas da Santa Casa de São Paulo (FCMSCSP) - São Paulo (SP), Brazil.

(C2015 by Anais Brasileiros de Dermatologia 
African studies report that an indeterminate number of albinos, especially children, have been victims of brutal assaults and murders related to witchcraft and superstition. In addition to the physical characteristics of albinos, the social structure and superstitious beliefs result in greater loss and social rejection. In Zimbabwe, albinos are called "sope", that means possessed by evil spirits; in Tanzania, they are also discriminated and called "nguruwe" and "zeru", which mean pig and ghost, respectively. Since childhood, their marked physical appearance when compared to the negro community and to family members, usually pigmented, brings problems of acceptance and social integration, as well as doubts regarding the paternity of the affected child. Cruz-Inigo et al. affirm that the first step to assist the albinos would be to educate society about the cause of albinism and diminish the prevalence of the disease, raising awareness of the fact that the biologic bond may increase the chances of acquiring certain genetic disorders. The researchers suggest informing the population, by means of radio programs and schools, regarding the implications of consanguineous relationships, demystifying the diseaseand promoting social integration. They also point out that the poverty and illiteracy prevalent in some parts of Africa contribute to erroneous beliefs. ${ }^{7}$

In Brazil, apparently the social reality of the albino is not as extreme as the A frican situation; however, it is probable that there are myths and social segregation al so. In this sense, it is important that the al bino and his family members be aware of the causes for his condition, of the psychosocial and medical implications, particularly the benefits afforded by protection against ultraviolet radiation and the consequences of solar exposure (premature aging and skin cancer).

Considering all the facts, the above mentioned conditions and the need to know the social reality of the albino in Brazil, as there is no research work being done in our midst and there is no reference to the theme, this study has the objective of assessing the quality of life of albinos cared for at our institution.

\section{CASESTUDY ANDMETHOD}

A cross-sectional study was carried out with a convenience sample. There was no sample cal culation, as all albino patients older than 18 years of age, registered in the outpatient clinic from the beginning in M arch 2010 to December 2013 (a total of 40 patients), participated. A non-probabilistic convenience sample of size equal to the number of existing cases was used as control group, with 40 healthy individuals who were accompanying non al bino patients.

The two groups were paired by sex and age.
The following groups of patients were excluded: individuals diagnosed with chronic disease or clinical conditions that are acknowledged as reducing quality of life (for example: rheumatoid arthritis, advanced osteoarthrosis, cardiac insufficiency NYHA III/IV); patients younger than 18 years of age, by norms of usage of questionnaire WHOQOL-BREF and patients from other countries, as we believe that the analysis of these data would not reflect the quality of life of al binos in Brazil. Thus, of the 40 al bino patients, 2 were excluded from the analysis for being of A frican origin.

Once the approval of the research ethic committee and the free informed consent were obtained, the 80 participants answered the questionnaire on quality of life WHO-QOL BREF.

Quality of life is described by the World Health Organization as "individuals' perception of their position in life in the context of the culture and value systems in which they live and in relation to their goals, expectations, standards and concerns". ${ }^{8}$

In order to assess quality of life, theabbreviated Portuguese version of the Assessment Instrument on Quality of Life of the World Health Organization, the WHOQOL-BREF, was used. Answering the questionnaire defines a numerical index representing the quality of life of the interviewed. The instrument was validated in Brazil, revealing satisfactory psychometric performance, internal consistency, discriminant validity, criteria validity, simultaneous validity and testing-retesting reliability. The score obtained in the questionnaire is calculated with the SPSS program and then submitted to statistical analysis (Non parametric Mann-Whitney test). ${ }^{9}$ 11 It contains 26 questions distributed into four domains: social relations, psychological, physical and environment. Each domain is composed of questions whose alternatives vary in spectrum from 1 to 5 .

In the physical domain, the facets involve pain and discomfort, energy and fatigue, sleep and rest, mobility, activities of daily living, dependence on medicinal substances and medical aids and work capacity. As regards the psychological domain, the quality of life is investigated seeking positive feelings as thinking, learning, memory and concentration, selfesteem, bodily image and appearance, and negative feelings as spirituality/ religion/ personal beliefs. The domain of social relations involves friends, relatives, acquaintances and colleagues, social support and sexual activity. In the environment domain, the investigated facets are physical safety and security, home environment, financial resources, health and social care, availability and quality, opportunities for acquiring new information and skills, participation in and opportunities for recreation/ leisure, physical environment and transport. 
Two aspects are of the greatest relevancein thelife of albinos: subnormal vision and presence of skin cancer.

\section{RESULTS}

Of the patients that participated in the study, $16(42.1 \%)$ mentioned they had already had skin cancer, $7(18.42 \%)$ had skin cancer at the time of study and $34(89.47 \%)$ mentioned visual deficit.

Theages of participants were distributed in the following manner: $57.7 \%$ (45 patients) were between 18 and 40 years of age, $28.2 \%$ (22 patients) between 41 and 60 years and 14.1\% (11 patients) were over 60 years of age (Table 1).

The analysis of results obtained in the questionnaires evidenced statistically significant difference in the physical domain, with $\mathrm{P}<0.001$, as described in table 2. (non parametric Mann-Whitney test). (Table 2)

TABLE 1: Distribution by gender

\begin{tabular}{llll}
\hline \multicolumn{3}{c}{ DISTRIBUTION BY GEN DER } \\
\hline Albinos & $\mathrm{N}$ & Female & M ale \\
& $\%$ & 24 & 14 \\
Controls & $\mathrm{N}$ & 63.20 & 36.80 \\
& $\%$ & 25 & 15 \\
\hline
\end{tabular}

Graphs from 1 to 4 illustrate median, maximum score and minimum score values, as well a the standard deviation obtained in each domain, using the results obtained in the WHOQOL-BREF questionnaire.

\section{DISQUSSION}

There is a program called Pro-albino at the Charity Hospital Irmandade Santa Casa de Misericórdia de São Paulo, where albino patients are seen for dermatological and ophthalmological care. From the beginning we have prioritized the primary and secondary preventive aspects regarding premature aging and skin cancer, as well as eye care. The prompt adhesion of a significant number of al bino children and adults led us to this investigation. What would be the impact of albinism on the quality of life of our patients? Although the number of studied cases was small, the assessment of the albino in the city of São Paulo, where the urban condition differs substantially from other regions in the country, may be an indicator of the need to expand this analysis to the diverse socioeconomic realities in Brazil.

The patient with oculocutaneous albinism has phototype 1 skin. Consequently, the albino has a high incidence of sunburns, elastosis, actinic keratosis (pre-malignant) and skin cancer. Skin cancer, for these patients who were not photoprotected and led a relatively exposed life, occurs in the phase of young adult, most of the times multiple and with an aggressive biologic behavior. In albinos there is an inversion regarding the type of skin cancer in relation to the general population, that is, a higher frequency of squamous cell carcinoma than basal cell carcinoma. ${ }^{4,12}$

TABLE 2:Table demonstrating results of two groups in the questionnaire WHOQOL-BREF by domain

\begin{tabular}{|c|c|c|c|c|c|c|c|}
\hline \multirow[b]{2}{*}{ DOMAINS } & \multirow[b]{2}{*}{ GROUP } & \multirow[b]{2}{*}{ MEAN } & \multicolumn{5}{|c|}{ Results WHOQOL } \\
\hline & & & MEDIAN & SD & MINIMUM & MAXIMUM & $\mathbf{P} *$ \\
\hline \multirow[t]{2}{*}{ PHYSICAL } & ALBINOS & 58.9 & 64.3 & 20.0 & 21.4 & 89.3 & $<0.001$ \\
\hline & CONTROL & 75.9 & 75.0 & 15.5 & 21.4 & 100.0 & \\
\hline \multicolumn{8}{|l|}{ PSYCHO } \\
\hline \multirow{2}{*}{ LOGICAL } & ALBINOS & 69.0 & 72.9 & 16.5 & 33.3 & 95.8 & 0.253 \\
\hline & CONTROL & 73.8 & 75.0 & 13.8 & 33.3 & 100.0 & \\
\hline \multirow[t]{2}{*}{ SOCIAL } & ALBINOS & 65.8 & 75.0 & 22.5 & 16.7 & 100.0 & 0.757 \\
\hline & CONTROL & 68.8 & 66.7 & 19.3 & 0.0 & 100.0 & \\
\hline \multirow[t]{2}{*}{ ENVIRONMENT } & ALBINOS & 47.6 & 50.0 & 15.8 & 6.3 & 78.1 & 0.056 \\
\hline & CONTROL & 54.7 & 53.6 & 14.2 & 25.0 & 96.9 & \\
\hline
\end{tabular}

*non-parametric Mann-Whitney test 


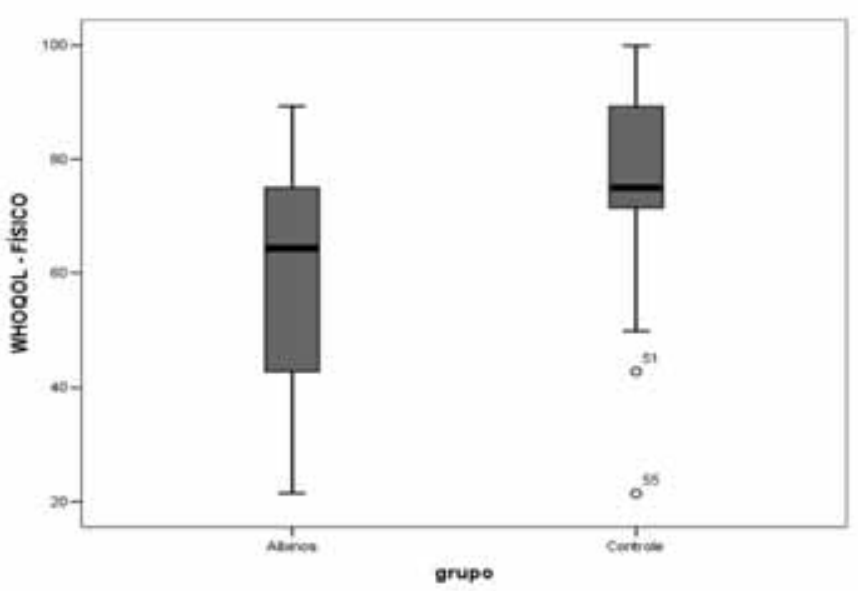

G RAPH 1: Box-plot of Physical domain of WHOQOL-BREF comparing results of the two analyzed groups

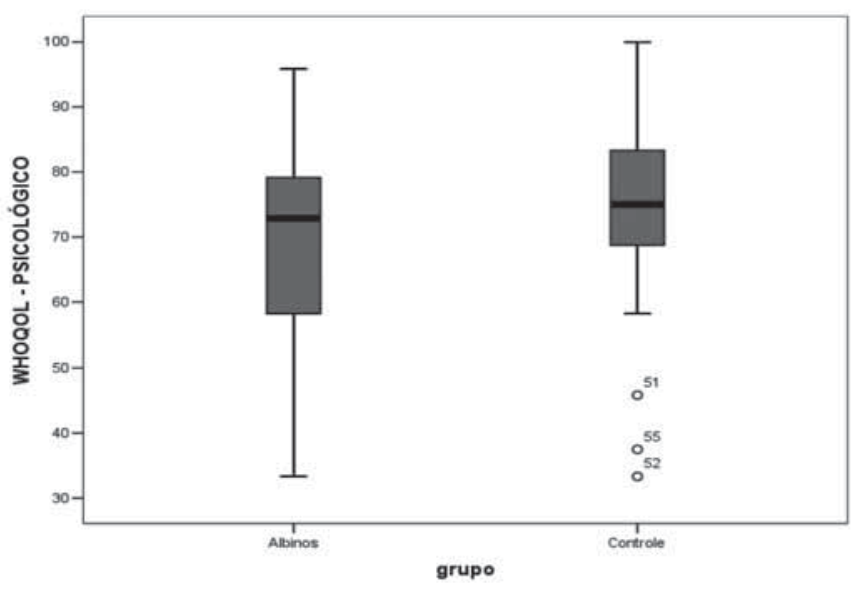

G RAPH 2: Box-plot of Psychological domain of WHOQOL-BREF comparing results of the two analyzed groups

In al binos diminishing visual acuity, refractive errors, translucent iris, nystagmus, foveal hypoplasia, fundus hypopigmentation and deviation of opticnerve fibers in the chiasm. This deviation is characterized by excessive crossing of fibers in the optic chiasm, which may result in strabismus and reduction of stereoscopic vision. Moreover, photophobia may be relevant. Therefore the albinos, also from the ocular point of view, become more vulnerable. ${ }^{6,13}$

This study evidenced alterations in quality of life, from the physical point of view, in the analyzed group of albinos. This points to skin lesions and decrease in visual acuity as responsible for the impact on the quality of life of these individuals. However, during the outpatient clinic appointments, there are frequent complaints of problems in personal, family and work relationships, where they often mention

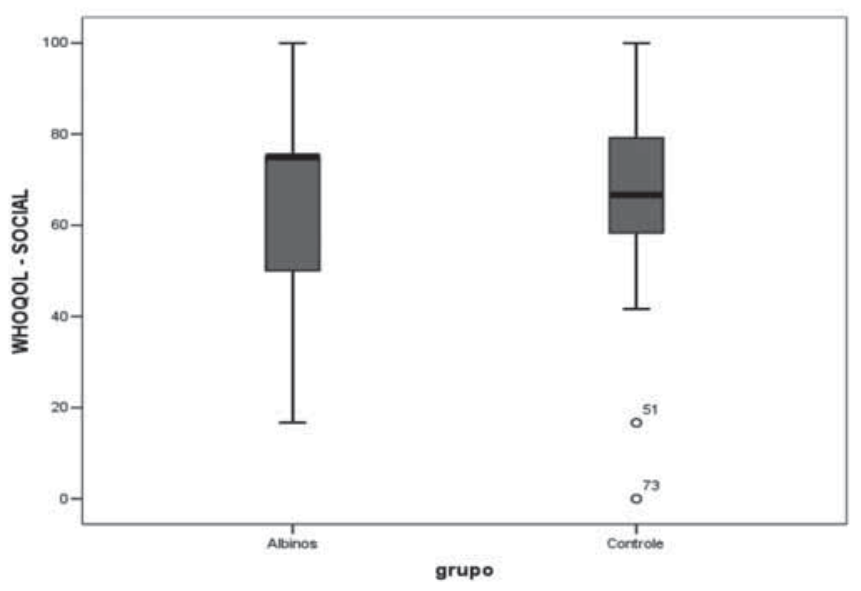

G RAPH 3: BoX-plot of Social domain of WHOQOL-BREF comparing results of the two analyzed groups

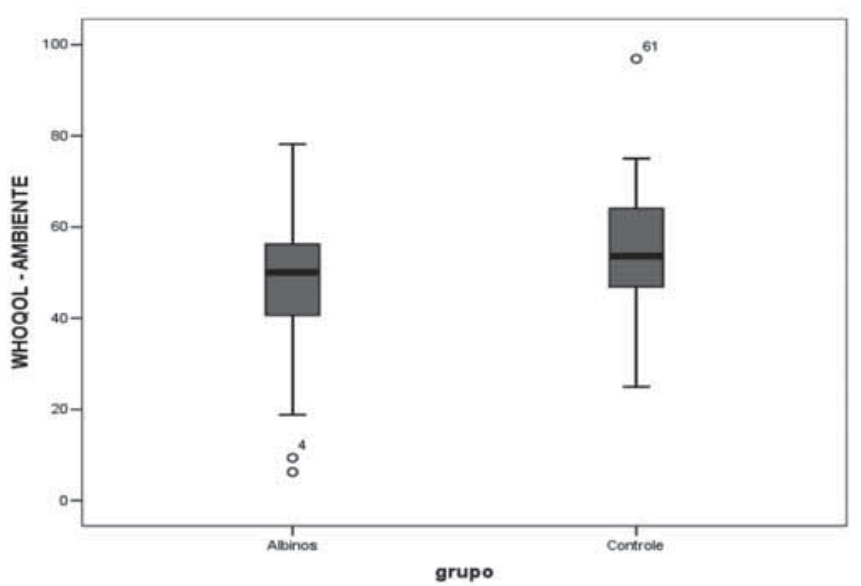

Graph 4: Box-plot of Environment domain of WHOQOL-BREF comparing results of the two analyzed groups

feeling as victims of prejudice. Nevertheless, these complaints did not lead to alterations in the analysis of the social domain, when compared to the results of the control group.

It is possible, therefore, that there are other alterations in the quality of life that were not sensitive to the instrument used in this study or that these complaintsdonotactually influencethequality of lifeof the population studied. The assessed group, although sharing the same origin, was quite heterogeneous regarding age, social class, level of education, as well as inclusion or not in the labor market. Such variables could only be better analyzed using a larger population. Studies with more homogeneous groups are necessary to reveal the medical and social needs of the al binos. 
Facing this context, it can be affirmed that it is necessary to implement better heal th carefor theal bino, considering biopsychosocial aspects, aiming not only at solar protection and treatment of skin lesions, but also family, genetic and professional guidance, such as night labor activities, besides promoting information and demystification of the disease.

\section{REFERENCES}

1. Summers CG. Albinism: Classification, Clinical Characteristics, and Recent Findings. Optom Vis Sci. 2009;86:659-62.

2. Okulicz J F, Shah RS, Schwartz RA, J anniger CK. Oculocutaneous albinism. J Eur Acad Dermatol Venereol. 2003;17:251-6.

3. Rocha LM, Moreira LMA. Diagnóstico Laboratorial do Albinismo Oculocutâneo. J Bras Patol Med Lab. 2007;43:25-30

4. Grønskov K, Ek J, Brondum-Nielsen K. Oculocutaneous albinism. Orphanet] Rare Dis. 2007;2:43

5. Moreira LMA, Moreira SC, Cabanelas ITD, Rocha LM. Perfil do Albinismo Oculocutâneo no Estado da Bahia. R Ci Méd Biol. 2007;6:69-75.

6. Hong ES, Zeeb H, Repacholi MH. Albinism in Africa as a public health issue. BMC Public Health. 2006;6:212.

7. Cruz-Inigo AE, Ladizinski B, Sethi A. Albinism in Africa: Stigma, Slaughter and Awareness Campaigns. Dermatol Clin. 2011;29:79-87.

8. The WHOQOL Group. What Quality of Life? World Health Forum. WHO: Genebra; 1996. p. 354-56

9. Fleck MPA, Louzada S, Xavier M, Chachamovich E, Vieira G, Santos L, et al. Aplicação da versão em português do instrumento abreviado de avaliação da qualidade de vida "WHOQOL-BREF". Rev Saúde Pública. 2000;34:178-83.

10. Fleck MPA, Louzada S, Xavier M, Chachamovich E, Vieira G, Santos L, et al. Aplicação da versão em português do instrumento de avaliação de qualidade de vida da Organização Mundial da Saúde (WHOQOL-100). Rev. Saúde Pública. 1999;33:198-205.

11. Fleck MPA, Leal OF, Louzada S, Xavier M, Chachamovich E, Vieira G, Santos L, et al. Desenvolvimento da versão em português do instrumento de avaliação de qualidade de vida da OMS (WHOQOL-100). Rev Bras Psiquiat. 1999;21:19-28.

12. Dessinioti C, Stratigos AJ , Rigopoulos D, Katsambas AD, et al. A review of genetic disorders of hypopigmentation: lessons learned from the biology of melanocytes. Exp Dermatol. 2009;18:741-9.

13. Kirkwood BJ. Albinism and its implications with vision. Insight. 2009;34:13-6.

\section{CONQUSION}

The low vision acuity added to skin lesions and the social stigma may contribute to thealterations in quality of life of albino patients. The results presented in this study demonstrate the vulnerability of the affected individual, the need for special care for this patient, as well as that further research is required on the theme, for a clearer view of aspects related to albinism.

\author{
M AILING ADDRESS: \\ Beatrice M ussio F ornazier V olpini \\ Rua Dr. Cesário M ota Jr., 112 \\ Vila Buarque \\ 01221-020 São Paulo, SP.
}

Tel: 11 2176-7000

E-mail: beatricevolpini@gmail.com

H ow to citethis article: Maia M, Volpini BMF, SantosGA, RujulaMJP. Quality of lifein patientswith oculocutaneous al binism. An Bras Dermatol. 2015;90(4):513-17. 